\title{
O Gênero Memorial na Construção Jdentitária Docente
}

The Genre Memorial in Identity Construction of the Teacher

Pollyanne Bicalho Ribeiro*

Resumo: Este trabalho visa a analisar a função do gênero memorial em processos formativos, focando principalmente as implicações de sua natureza híbrida para a construção identitária do sujeito docente e de seu grupo. Por colocar em cena e encenar saberes discursivamente construídos e desconstruídos pelo sujeito professor, interessou-nos analisar modos de dizer o ser/fazer e seus efeitos na interação, em meio a situações de ensino/ aprendizagem. O corpus é (re)velador à medida que traz à tona respostas da relação do sujeito professor consigo, com o outro e com o conhecimento, advindas de processos metacognitivos, circunstanciados, garantidos pelo gênero memorial. É analisada a configuração do referido gênero, principalmente, como a correlação existente entre os elementos de sua organização, as condições de produção (as circunstâncias de enunciação e seu contexto sócio-histórico) e os sujeitos sociais participantes do processo discursivo em questão. O quadro teórico norteador deste trabalho reúne estudos a respeito das representações sociais, identidade (Pavloski, Py), de formação e do funcionamento dos discursos produzidos na interação social (Bakhtin, Filliettaz, Machado), através do gênero Memorial (Passeggi).

Palavras-chave: Construção identitária. Gênero memorial. Educação de professores.

* Doutora em Linguística e Língua Portuguesa pela PUCMinas (2008). Professora Doutora Adjunto IV_UFC.Contato: pollyanne_br@yahoo.com.br. 
Abstract: The objective of this work is to analyze the function of the memorial genre in formation processes, focussing, mainly, the implications of its hybrid nature for the identity construction of the teacher subject and his group. For putting in the scene and staging discursively knowledge constructed and deconstructed by the teacher subject, we had interest to analyze telling ways the to be/to do and its effects on interaction, in the midst of situations of apprenticeship/learning. The corpus is revealing while adressing answers of the relation of teacher subject, with himself, with the other and with the knowledge obtained through circumstanced meta cognitive process, guaranteed by the memorial genre. It is analyzed the configuration of the mentioned genre, and, mainly, as the existing correlation between the elements of its organization, the production conditions (enunciation circumstances and its historical-social context) and the participant social subjects of the discursive process in study. The guiding theoretical framework of this work brings studies concerning the social representations, identity (Pavloski, Py), formation and the functioning of the produced discuses in the social interaction (Bakhtin, Filliettaz, Machado), through Memorial genre (Passeggi). Keywords: Identity construction. Genre memorial. Teachers education.

\section{Introdução}

A influência do gênero memorial para a análise de modos de dizer o trabalho docente deve ser vista como fator imprescindível para que se possa compreender o desenho que vai se delineando ao longo da prática formativa. Nossa proposta aqui é elucidar as características do gênero memorial, compreender o seu funcionamento, a sua função social e a relação entre os elementos constituintes para a emergência do discurso do professor em formação.

A tentativa é de flagrar aspectos do processo contínuo de escrita visando a identificar a natureza do gênero em questão, considerando o que é posto pelos sujeitos a respeito da experiência da produção dos memoriais, como também o que se esboça, o que se evidencia como traço do gênero. 
A atenção se volta para as especificidades do gênero memorial no contexto do Projeto Veredas ${ }^{1}$.

Para isso, apoiamo-nos sobretudo nos pressupostos bakhtinianos. Particularmente, no conceito de gênero do discurso.

O emprego da língua efetua-se em forma de enunciados (orais e escritos), concretos e únicos, proferidos pelos integrantes desse ou daquele campo da atividade humana. Esses enunciados refletem as condições específicas e as finalidades de cada referido campo, não só por seu conteúdo (temático) e pelo seu estilo da linguagem, ou seja, pela seleção dos recursos lexicais, fraseológicos e gramaticais da língua mas, acima de tudo, por sua construção composicional [...] Evidentemente, cada enunciado particular é individual, mas cada campo de utilização da língua elabora seus tipos relativamente estáveis de enunciados, os quais denominamos gêneros do discurso. (BAKHTIN, 2003, p. 261-262).

Para Bakhtin, o emprego da língua se faz sob a forma de enunciados ${ }^{2}$ e, portanto, o enunciado é "unidade real da comunicação discursiva" (2003, p. 269). Ao defender o enunciado como unidade da atividade comunicativa, o autor contrapõe a ideia de enunciado à de oração, salientando que essa última não considera a alternância dos sujeitos do discurso, o contexto de produção, os enunciados alheios, enfim, ela não suscitaria a atitude responsiva dos interlocutores.

Essa noção de enunciado, de acordo com os pressupostos dialógicos, abarca o contexto verbal e o contexto extraverbal (aspectos situacionais,

1 Tratou-se de um projeto-piloto em educação a distância, coordenado pela Secretaria de Educação do Estado de Minas Gerais - SEE/MG -, que contou com a colaboração de 18 instituições, públicas e privadas, de ensino superior, para o seu desenvolvimento. Tal projeto findou-se em 2005, conferindo aos participantes a graduação de Normal Superior. Ao longo do Veredas, os professores-cursistas produziram um memorial cujo objetivo era relatar as experiências vivenciadas na prática formativa.

${ }^{2}$ Conforme notas do tradutor, Bakhtin não faz distinção entre enunciado e enunciação, o autor emprega o mesmo vocábulo (viskááivanie) para se referir ao ato de produção do discurso e ao discurso propriamente dito. 
históricos, ideológicos), ou seja, ele traz à tona, concomitantemente, o que há de peculiar da situação enunciativa concreta e elementos sociodiscursivos estabilizados nas e pelas práticas comunicativas ao longo da História. Através do enunciado é que o outro se instaura na dinâmica discursiva. Ele garante o fluxo de múltiplas vozes que ecoam da alternância dos sujeitos do discurso na interação. Por figurar como unidade da comunicação discursiva, o enunciado elucida especificidades das práticas sociais nas quais ele se constituiu.

A partir desse quadro teórico, faz-se uma proposta de reflexão sobre os elementos essenciais (conteúdo temático/estilo/estrutura composicional) do gênero discursivo para a captação da dimensão dessa definição a que Bakhtin se reporta. Em agindo dessa forma, a compreensão do gênero discursivo pode subsistir a identificação da natureza do gênero memorial e, portanto, o seu funcionamento nas práticas sociais, aqui, particularmente, os seus efeitos para a construção identitária docente.

A produção do memorial é um exercício contínuo de escrita reflexiva. Lidar com as condições de produção do gênero em questão exige um constante e gradativo agir reflexivo. $\mathrm{O}$ memorial se apresenta como uma vitrine já que dá visibilidade a processos e produtos relacionados ao saber dizer a prática docente e/ou a prática formativa. A escrita reflexiva cumpre a função de levar o sujeito a tomar consciência das suas mudanças e das mudanças do grupo de pertença.

\section{A Construção Identitária Instanciada pelo Gênero Memorial}

Sabemos que o sujeito é (re)constituído de maneira incessante nas e pelas diversas práticas discursivas das quais participa. Não há uma identidade fixa, única, homogênea; há uma organização movente, múltipla e heterogênea, que dará os contornos nada precisos do sujeito inscrito no mundo social. A todo momento, revisitamos os nossos quadros de referência, desestabilizamonos, transformamo-nos, reinventamo-nos; não só a nós como sujeitos envolvidos com nossas rotas particulares, mas como membros de um grupo social.

Apesar de a identidade ser fruto de um processo dinâmico, no qual se reitera e atualiza os fragmentos identitários tal como um caleidoscópio, há discursos coercitivos que corroboram para a construção de padrões de 
comportamento e posicionamento, o que não significa dizer que inexistem escolhas para o sujeito, mas certas tendências de pensamento, determinadas crenças, enfim, o seu agir sofre influência desses padrões.

A imposição de padrões comportamentais externos produz uma limitação que é constantemente entendida pelos indivíduos como uma autolimitação, o que dificulta o exercício da própria individualidade. Consequentemente, a supremacia do Não-eu sobre o Eu cria a ilusão de que o mundo é externo ao sujeito quando, na verdade, o universo material se constrói a partir dele e por meio da linguagem. (PAVLOSKI, 2012, p. 21).

Assim, experiências, que promovam um olhar para si, fomentam um movimento de busca preeminente do Eu e do Não-eu e, ao mesmo tempo, a identificação do Nós e do Não-nós. No percurso de idas e vindas, a identidade social se reafirma, padrões estabelecidos são colocados em xeque, através do descortinamento de crenças, opiniões, pensamentos, uma nova ordenação é estabelecida.

Qualquer experiência de mudança, obviamente, coloca à tona modelos, visto que eles são (re)avaliados, mas imediatamente criamos novos modelos a partir do acervo sócio-histórico que dispomos, já que "na verdade, nenhum molde foi quebrado sem que fosse substituído por outro" (BAUMAN apud PAVLOSKI, 2012, p. 23)

A prática formativa, portanto, instaura, a partir da avaliação de traços encontrados, uma atualização de traços, de material simbólico imprescindível para o processo de (re)constituição identitária. Na discursivização desse processo, torna-se possível analisar o gerenciamento de vozes, a fim de entendermos modos de significar o seu agir e o de seus pares.

A identidade do sujeito docente se configura em consonância com o lugar concedido ao locutor no discurso e tal posição discursiva assumida pelo locutor não é estática; ao contrário, é plástica, ela vai se deslocando ou se modelando a partir da demanda surgida ao longo da prática formativa. As imagens são constituídas a partir das representações de si, do seu grupo ou de outro grupo. Desse modo, é a partir do quadro de referência comum sobre a figura que é colocada em cena (figura docente) que o ser social, 
tomado em cena, se constitui. A imagem do ser docente é engendrada a partir do acervo representacional, que deve ser entendido como um sistema de interpretação da realidade.

A partir da tese, defendida por Bakhtin (2004, p. 35-36), de que o dialogismo é aspecto constitutivo da linguagem e da produção de sentido, “julgando-nos do ponto de vista dos outros, tentando compreender, levar em conta o que é transcendente à nossa própria consciência: assim levamos em conta o valor conferido ao nosso aspecto em função da impressão que ele pode causar em outrem”. Assim, para que se possa analisar a constituição identitária do sujeito docente construída na prática formativa, é de fundamental importância considerar o(s) outro(s), ou seja, deve-se examinar as inter-relações dos sujeitos sociais na enunciação e, por sua vez, os papéis sociais assumidos por eles na atividade comunicativa.

Acreditamos que lidar com o dito, instanciado pelo gênero memorial, permite-nos avaliar maneiras de significar o magistério, o fazer docente, assim como, os efeitos disso para a relação ensino-aprendizagem. Conforme Bakhtin (2003, p. 34),

... a compreensão é uma resposta a um signo por meio de signos. E essa cadeia de criatividade e de compreensão ideológicas, deslocandose de signo em signo para um novo signo, é única e contínua: de um elo de natureza semiótica (e, portanto, também de natureza material) passamos sem interrupção para um outro elo de natureza estritamente idêntica. (BAKHTIN, 2003, p. 34).

Nesse sentido, é possível afirmar que os signos são indicadores de aspectos sociais, históricos, ideológicos de determinado grupo social. Ao elegermos o grupo docente, esperamos compreender o processo pelo qual o indivíduo referencia a si como professor, mas também, na assunção de porta voz, como o seu grupo de pertença é referenciado. Diante disso, todo o processo de mobilização/atualização dos signos sobre a figura do professor corrobora para o entendimento da construção identitária do dever a ser docente.

No âmbito do memorial, transparecem os enfrentamentos, os embates, as reformulações, as expectativas, as frustrações. Tudo isso conferirá 
traços para o delineamento da identidade da figura docente e, por conseguinte, acarretará efeitos na prática educativa.

À propósito, "sabemos que cada palavra se apresenta como uma arena em miniatura onde se entrecruzam e lutam os valores sociais de orientação contraditória" (BAKHTIN, 2004, p. 66). Assim, vale afirmar que a palavra é potência, impregna-se de significados na relação eu-outro, a palavra "revelase, no momento de sua expressão, como o produto da interação viva das forças sociais. É assim que o psiquismo e a ideologia se impregnam mutuamente no processo único e objetivo das relações sociais" (BAKHTIN, 2004, p. 66).

Analisar vozes docentes pode levar os professores e formadores a problematizarem o seu fazer e, portanto, transformarem determinados conhecimentos ou o estabilizarem. Tais efeitos acabam cooperando para a ressignificação do trabalho docente e para o aprimoramento das condições subjetivas e objetivas do agir em sala de aula.

O gênero memorial, portanto, apresenta-se como arena reveladora de aspectos identitários discursivamente colocados pelos professores em formação ao falarem de si e, por conseguinte, da sua profissão.

Vejam-se, então, como as professoras-cursistas concebiam o gênero memorial, sua função para a prática formativa no âmbito do Projeto Veredas, as impressões sobre o processo de elaboração do referido gênero.

01 - Quero fazer destes escritos uma janela para o futuro, uma análise, um relato profundo do meu trabalho como professora. Intimidade com as palavras? Não tenho, mas com certeza virá com o tempo. Aliás, o tempo vem transformando e muito a sociedade, basta compararmos a de ontem com esta, voraz, que nos rege hoje.

Prof. $01^{3}$

${ }^{3}$ Os dados foram retirados de um corpus de 40 memoriais analisados para a pesquisa de doutorado apresentada ao Programa de Pós-graduação da Pontifícia Universidade Católica de Minas Gerais. Para essa análise em particular, selecionamos 10 memoriais dentre os 40 memoriais outrora investigados. 
A locutora, referindo-se ao memorial, diz querer torná-lo uma janela para o futuro. O vocábulo janela sugere, nesse contexto, abertura, entrada. Daí é possível interpretar que, para a locutora, o memorial é um meio, um espaço que garantirá a projeção, o acesso ao futuro. Nota-se que a locutora estabelece uma relação analógica entre memorial e janela para o futuro, visando a qualificar positivamente o que vem a ser o papel do memorial para ela.

Conforme Filliettaz (2000), a analogia é reveladora de operações no plano cognitivo e social concernentes à produção de sentidos em práticas comunicativas. Assim, elas cumpririam a função de trazer à tona conhecimentos edificados no nível individual e coletivo e viabilizariam a atividade interpretativa na (re)elaboração de objetos de discurso nas práticas de linguagem face à aproximação de domínios semânticos a priori distintos. A relação instaurada entre os domínios colocados na cena enunciativa pode facilitar a compreensão, a significação do tópico discursivo demandado pela atividade de linguagem. Nesse processo, seja por traços afins de um domínio e outro, seja pela distinção, há um delineamento do objeto topicalizado por comparação.

Doise e Palmonari (1986, p. 22, tradução nossa), no contexto da TRS, descrevem o processo de ancoragem como "colocar um objeto novo no quadro de referência bem conhecido para poder interpretá-lo.” Diante dessa assertiva, é possível afirmar que a analogia se apresenta como uma operação de ancoragem à medida que permite a interpretação de um dado objeto tendo em vista a associação a outro objeto. Nesse processo, traços, elementos são revistos, avaliados e ressignificados e, assim, (re)elaborados no decorrer da interação.

É corriqueiro o uso da analogia nos memoriais analisados. As professoras-cursistas constantemente utilizavam esse recurso linguístico para descrever, abordar objetos relacionados à prática docente e/ou à prática formativa.

O retorno ao excerto já destacado merece atenção. A locutora continua qualificando o memorial expondo o seu desejo de tê-lo como um meio de análise, um relato profundo do seu trabalho como docente. Assim, para a locutora, o memorial se apresenta como um instrumento capaz de favorecer o autoconhecimento, a ponto de trazer à tona questões profundas sobre o trabalho que desenvolve como docente. 
Em seguida, a locutora traz um dado através de um questionamento que conduz o processo reflexivo: intimidade com as palavras? E, daí, ela acrescenta: Não tenho, mas com certeza virá com o tempo. Nessas sequências, a locutora expõe uma possível dificuldade quanto ao processo de escrita exigido pela elaboração do memorial. Em seguida, ela se mostra confiante com relação à aquisição da necessária qualidade face ao transcorrer do tempo. Ao fazer a constatação mencionando o vocábulo tempo, a locutora amplia sua reflexão dizendo ser o tempo o responsável por mudanças na sociedade. Ademais, demonstra perceber que a escrita é algo processual, cujo aprimoramento deva vir com o tempo.

Ressalta-se que, primeiro, o excerto revela um centramento da narrativa no aspecto pessoal da locutora, na sua limitação e, após, há um descentramento para questões mais gerais, de âmbito coletivo. Esse movimento, definido pelas condições de produção, foi percebido ao longo da análise do corpus. Constantemente, notou-se nos memoriais um falar de si como situação introdutória para o falar de nós ou para o falar deles ou vice-versa. Nesse quadro, tanto questões mais privadas vão sendo tratadas, como também as mais públicas. No centramento e descentramento, elaboram-se conhecimentos, comportamentos, posicionamentos, processos metacognitivos vão sendo instaurados.

Sobre o processo metacognitivo e a função do memorial na dinâmica desse processo, a locutora faz uma citação que ilustra bem o papel do memorial na formação desses professores, e parece que a própria enunciadora identifica essa função do gênero ao eleger e expor em sua narrativa o seguinte excerto de Carlos Drummond: "Não, meu coração não é maior que o mundo. Ele é muito menor. Nele não cabem nem as minhas dores. Por isso preciso tanto me contar."

02 - Neste momento no Veredas, estamos sendo orientados a continuar o trabalho de ação-reflexão-ação ao longo de toda vida profissional. O diário reflexivo funciona como uma espécie de registro crítico, preliminar de nossa prática de modo que nós possamos dispor de informações confiáveis que irá servir de subsídios para o contínuo aprimoramento de nossa prática pedagógica. Constitui uma autoavaliação contínua que nos permitirá procurar novos conhecimentos para reorientar nossas ações docentes.

Prof. 01 
A mesma locutora, mais adiante em seu texto, discute a função do memorial para a prática pedagógica. $\mathrm{O}$ excerto se inicia pela menção da importância do trabalho calcado na ação-reflexão-ação. Na locução que se segue, a Prof. 01 se refere ao memorial como um diário reflexivo. Demonstra, com sua exposição, que o referido gênero se adequaria aos propósitos do Veredas no sentido de favorecer a ação-reflexão-ação. Ela continua detalhando a função do gênero salientando que ele funcionaria como um registro crítico que daria suporte ao aperfeiçoamento da prática pedagógica e, ainda, como autoavaliação que possibilitaria o (re)direcionamento da prática docente.

03 - Fazendo o memorial, estou reconstruindo o meu percurso na escola e esclarecendo as próximas etapas do meu trabalho (muito satisfatório).

$[\ldots]$

Escrevendo meu memorial, pude perceber as dimensões que nós professores temos como profissionais da educação. O professor deve como pensador, ser capaz de ressignificar criticamente sua prática e as representações sociais, sobre o campo de atuação; como cidadão, fazer parte de uma sociedade e de uma comunidade percebendo que, como pessoa, há direitos e deveres comuns a todos.

Prof. 02

04 - O registro do Memorial nos faz repensar nossas ações sobre a prática pedagógica. O nosso papel de professor, educador e mediador entre o conhecimento e o aluno como 'pessoa'.

Prof. 03

05 - Ao escrever sobre o nosso processo de formação estamos analisando o presente em função do momento em que estamos vivendo, de nossa experiência no Veredas, dos estudos, das nossas leituras mais recentes, tentando refazer a nossa trajetória e refletir sobre ela.

Prof. 04

06 - Através do memorial, passeamos com nosso olhar atento pelos anos que fazem parte de nossa história. Descobrimos que a educação de hoje é uma construção histórica, resultado das buscas e incertezas do passado, e que ainda tentamos novas-velhas soluções para velhos-novos problemas. Educação é assim: repleta de ambiguidade, de contradições.

Prof. 05 
É possível observar, dos excertos, que as professoras-cursistas conferem ao memorial um meio ideal para o processamento de operações metacognitivas. Ele ambienta reflexões, avaliações e ressignificações de objetos relacionados ao âmbito pessoal e/ou profissional. Há grifos para as sequências "pude perceber as dimensões que nós professores temos como profissionais da educação" (excerto 03); "nos faz repensar nossas ações sobre a prática pedagógica" (excerto 04); "estamos analisando o presente em função do momento em que estamos vivendo" (excerto 05) e "descobrimos que a educação de hoje é uma construção histórica" (excerto 06). As sequências - e, particularmente, os verbos destacados confirmam que as locutoras reconhecem a função diagnóstica e formativa do memorial. Os textos destacados evidenciam que, em razão da continuidade e flexibilidade, peculiares ao referido gênero, a avaliação e a autoavaliação, favorecidas pelo memorial, são fundadas no processo.

Conforme Passeggi (2006, p. 10), a metacognição "se dá pelo distanciamento da maneira de pensar da própria instituição e dos modelos por ela impostos. A formação 'autêntica' através da escrita autobiográfica exige esse deslocamento da consciência e se faz na investigação do pensar". A partir dessa constatação, a autora conclui: "daí a necessária lucidez da coresponsabilidade na conscientização e interpretação da vida na autobiográfica.".

O memorial torna visível o processo de inserção na prática acadêmica e, ainda, a tomada de consciência das mudanças sofridas ao longo da prática formativa. O reconhecimento que aí se estabelece é de toda ordem, como o de se ver como membro da academia, como membro do grupo de docentes, como cidadã, como sonhadora, como mãe etc. Na constituição de papéis sociais, valores são associados e dissociados, contradições emergem, percursos para a busca de sentidos são (re)velados.

07 - Baseado em meus relatos até aqui o que declaro junto ao meu trabalho pedagógico é que está ocorrendo uma evolução e um retorno favorável à minha prática.

Prof. 06 
08 - Ao escrever meu memorial, pude observar a evolução de minha prática pedagógica. Foi uma reflexão sobre o que fiz, faço e ainda posso fazer enquanto professora. A Filosofia da Educação não apresenta receitas prontas para as soluções de problemas. Cabe ao educador refletir o fazer educacional, como mediador entre o conhecimento e o aluno, gestor da turma, pelo currículo real que ele desenvolve e organizador do trabalho escolar, a partir da prática pedagógica, com os saberes de área, intersubjetivos e fundamentais, com noções de sujeito autônomo com relação ao mundo, com ele mesmo e com o outro, com atitudes de respeito aos valores, exercendo sua liberdade com moral e ética. Prof. 03

As locutoras salientam que identificaram uma evolução no tocante à sua prática pedagógica e atribuem ao memorial a possibilidade de perceber essa mudança. O memorial, portanto, funciona como um registro (conforme excerto 09, a seguir) que viabiliza comparações de comportamentos pregressos diante de ocorrências atuais. Nessa dinâmica, atualizam-se concepções, representações e as enunciadoras (re)veem pontos de vista, opiniões.

09 - Muitas coisas eram feitas, porém não registradas. Aí está a diferença. Esses registros é que têm melhorado a minha prática está sendo mais prazeroso. Prof. 05

Para Py (2004, p. 15, tradução nossa), “a opinião seria o resultado de uma solicitação exterior portando crenças em um ponto qualquer da sua trajetória." A opinião, então, pode ser entendida como o limiar entre as experiências coletivas e individuais, como o ponto mais sensível, mais palpável entre as representações mentais e sociais, entre aquilo que é, ao mesmo tempo, mais peculiar à singularidade do sujeito, como também à memória coletiva. O interesse é operar com as opiniões das professoras-cursistas para compreender o público em questão e, pelo elo, analisar o discurso docente emerso sob as condições determinadas pela prática formativa.

10 - Bem, agora estou com dificuldades em desenvolver o memorial. Como eu já relatei, tudo é tão novo, que tenho medo de escrever bobagens e supervalorizar fatos rotineiros.

Prof. 08 
Esse excerto nos faz pensar em duas questões. A primeira questão diz respeito à influência da dimensão privada sob o gênero memorial. Através do exposto, é notório que, apesar da insegurança diante do novo e, nesse caso, também o memorial se apresenta como novidade, a locutora percebe que o âmbito privado participa da natureza do gênero. Prova disso é a sequência tenho medo de escrever bobagens e supervalorizar fatos rotineiros que evidencia a identificação constitutiva do gênero memorial. Significa que há espaços, aberturas para suscitar questões do âmbito privado. Todavia, essa abertura não é plena, visto que as condições de produção, incluindo os parâmetros reguladores de elaboração do gênero, determinam as escolhas linguísticas e discursivas na atividade comunicativa.

Outra questão relacionada ao gênero memorial diz respeito à atividade de escrita. Este gênero exige um processo de escrita contínua e, portanto, o sujeito que enuncia deve lidar com a produção textual, com as dificuldades do ato de escrever, além, obviamente, da complexa ação de se expor. Ora, é sabido o quão é difícil expressar os sentimentos, as emoções, (re)contar questões pessoais, mas o memorial se apresenta como um gênero adequado para o desenvolvimento da habilidade da escrita já que ele é continuamente construído e, gradativamente, vai ganhando consistência e solidez. O exercício da escrita leva o sujeito/autor a desmistificar o ato de escrever e de se colocar enquanto protagonista da história narrada.

Nesse processo, o sujeito envolvido com a elaboração vai tomando consciência das suas limitações linguísticas e discursivas e vai se aprimorando, aperfeiçoando-se. Gradativamente, ele assume a condição de eu-narrador e opera com recursos da língua(gem) para dar vazão à sua voz no universo de discursos proferidos no âmbito acadêmico e/ou docente. $\mathrm{Na}$ ação autoral, o professor-cursista volta seu olhar para si, para o outro, para o passado, para o presente, para o futuro, traduz experiências individuais e coletivas em palavras e, nessa dinâmica, (re)inventa-se.

Trata-se de uma oportunidade de a professora-cursista se colocar na condição dos seus alunos e perceber os problemas em torno de atividades de escrita propostas em sala de aula. O memorial pode também cumprir a função de levar o professor a objetivar o papel da escrita e, ainda, de identificar as dificuldades peculiares a essa prática. A situação é propícia para a professoracursista aprender com ela mesma, tirar conclusões a partir da sua própria 
experiência. Aliás, é notória a evolução das professoras-cursistas na prática de escrita. É possível acompanhar a melhora gradativa no tocante às escolhas linguísticas, textuais e discursivas empreendidas nos memoriais. Há relatos das próprias professoras-cursistas que narram a evolução percebida na escrita, conforme excerto a seguir.

11 - O memorial foi uma prática preciosa para o aperfeiçoamento da minha escrita que muito contribuiu na elaboração da monografia. Se pretendemos tornar nossos alunos cidadãos leitores e capazes de expressar-se inclusive por escrito, faz-se necessário propor a eles que escrevam sobre si mesmos, suas vidas, o mundo, foi isso que procurei exercer com frequência e adequadamente no Veredas tanto na fala como na escrita; até fazendo curso de computação, coisa que não pensava jamais fazer e adorei!

Prof. 08

Ademais, o memorial não se esgota enquanto texto no momento da escrita. Por ser a sua elaboração contínua, o locutor pode retomar pontos, delinear, precisar, se contradizer etc. Ele não deve exaurir os pontos a serem abordados em um único momento da produção textual. Assim, ao longo do relato, questões são constantemente revistas e (re)coladas, o que, por sua vez, instala-se um movimento permanente do dizer e do (re)dizer.

12 - Quando terminei o ensino fundamental (5. ${ }^{a}$ a $8{ }^{a}$ séries) quis fazer o científico e acabei caindo de bobeira no magistério. No decorrer do curso acabei gostando, gostei tanto que sempre que tinha oportunidade era professora voluntária. Fiz minha monitoria em uma escola grande, estadual [...] para eu me sentir mais próxima dos alunos, meus futuros alunos, já que eu era futura professora. $[\ldots]$

Com a pouca ou nenhuma experiência fui em frente.

$[\ldots]$

Com isso, os alunos perceberam que eram capazes que tinham habilidades e, o melhor, sentiram que eles eram importantes para seus pais, pois a partir daí eles começaram a bater na porta para saber o desenvolvimento de seus filhos.

$[\ldots]$

O magistério já não era mais uma bobeira e sim uma conquista entre professor, aluno, pais.

Prof. 05 
A locutora afirma ter entrado no magistério de bobeira. Em seguida, ela relata que se viu envolvida com o curso a ponto de se tornar professora voluntária. Nas transcrições seguintes, há exposições do seu percurso até se tornar de fato uma professora. Após exemplificar situações relacionadas à prática docente, ela retoma o vocábulo bobeira e o recoloca agora para negar o contexto antes elucidado de que o magistério seria uma bobeira. Na última parte, é possível identificar a relação adversativa entre bobeira e conquista, ou seja, o que antes era uma bobeira passa a ser visto como uma conquista. Esse excerto ilustra o processo elaborativo do memorial concernente a uma constante (re)avaliação de apontamentos e (re)tomadas de posicionamentos.

Passeggi (2006, p. 2) define o memorial como "narrativas de vida institucionalizadas", que "instauram a problemática da reinvenção de si mesmo, num contexto de injunção institucional”. O memorial deve ser analisado, sim, como um gênero acadêmico, mas também como um espaço em que "transparecem" reflexões sobre experiências sociais pessoais e/ou coletivas.

Nessa instância, há negociações entre o que significa para a instituição (discurso constituído), para a Agência Formadora e o que significa para o sujeito docente que vivencia a formação (discurso constituinte). Nas negociações de significados, há mudanças tanto no plano institucional, quanto no plano individual e, nesse enfrentamento, objetos da prática pedagógica vão sendo (re)modelados. No quadro instaurado, torna-se possível identificar o que é canônico, conhecimentos reiterados e o que foge a isso, irregularidades. Consequentemente, é possível notar as estratégias de (re)formulação, (re)adaptações às coerções impostas pela instância acadêmica no espaço movediço da autonarrativa.

Segundo Machado (2004, p. 58), “mesmo sendo incontornáveis, as convenções geram a violação das regras implícitas que instituem ou se impõem a nós como coerções rígidas ou põem à nossa disposição um leque de possibilidades para o agir". O professor-cursista, ao se envolver com a prática comunicativa, deve operar no limiar das convenções determinadas pela Agência Formadora, pelas restrições do gênero memorial e pelo animus de se expor, de narrar suas vivências. Nessa dinâmica, há rupturas, reiterações, (re)ações e, por assim ser, desenha-se a dimensão formativa.

O processo formativo contou também com a mediação do Tutor. $\mathrm{O}$ Tutor cumpriu o papel de aguçar o olhar do professor-cursista para questões 
relevantes, sobre o mundo pessoal e profissional. A mediação do Tutor foi relevante à medida que colaborou para a expressão dos sujeitos de suas percepções e subsidiou operações de reconhecimento de aspectos que outrora o locutor não se atentaria ou não enxergaria.

Desse modo, o Tutor, ao ler os memoriais, propôs questões, salientou dados importantes. Enfim, instigou o processo formativo amparado pelo gênero em questão e, ainda, auxiliou a ordenação do caótico mundo interior do professor-cursista a ser traduzido em palavras. As intervenções do Tutor foram imprescindíveis para ajudar o locutor a encontrar o "tom" no que tange a operar com as emoções e com as demandas acadêmico-científicas.

13 - Após a primeira correção do memorial por você (minha querida tutora Eliana), sinto mais segurança pra continuá-lo, com certeza, com mais vontade e entusiasmo.

Prof. 04

14 - Você [tutora] me perguntou qual é o papel da escola. Para mim, o papel da escola é oferecer ao aluno que desenvolva seus conhecimentos para se formarem seres dignos de cidadania. Se a escola é espaço de socialização, ela deve oferecer aos alunos as experimentações, interação, desenvolvimento de seus conhecimentos e cultura.

Prof. 07

Na construção de sua narrativa, a locutora recorre também a estratégias linguísticas que cooperam para o engajamento do leitor/tutor no processo enunciativo. Os excertos descritos linhas atrás exemplificam essa constatação, visto que demonstram a proximidade entre os interlocutores marcada pelo diálogo estabelecido entre a professora-cursista e o Tutor. O que se observa é que o tutor/interlocutor exerce um papel ativo no processo enunciativo, pois orienta certas questões, julgadas relevantes para o processo formativo, a serem elucidadas no texto. O locutor parece contar com o tutor/interlocutor como parceiro ou como membro e, por assim ser, de certo modo, eles devem compartilhar dos mesmos interesses comunicativos e dos mesmos domínios de referência no processo interpretativo.

Nesse sentido, é possível afirmar que, na elaboração do memorial, tanto o locutor, quanto o interlocutor se inscrevem na tessitura do enredo, 
cada qual, obviamente, com diferentes graus de comprometimento e engajamento. Por conseguinte, o que dizer, como dizer, por que dizer são, a todo momento, (re)configurados em razão das expectativas dos interlocutores e são passíveis de (re)negociações ao longo da prática comunicativa.

Aos poucos, a ação de se (re)contar se torna mais familiar e mais natural. Os professores-cursistas hesitam menos em se expor e aprendem a (re)velar suas descobertas de maneira mais objetivada e de acordo com os parâmetros acadêmicos. Com a prática advinda do processo de elaboração, o locutor se vê mais em condições de decidir o que é legítimo ou não dizer no contexto delineado pelo gênero. A todo o momento, a imagem de si estará suscetível de julgamentos e qualquer exposição, necessariamente, cooperará para a constituição do ethos do professor em formação.

$\mathrm{O}$ ato de se conhecer é nutrido pelas experiências pessoais, profissionais e acadêmicas. O locutor não só tece sua história de vida, como dos seus pares: ele rememora e/ou reinventa acontecimentos do âmbito intrapessoal, intragrupal e intergrupal. Cada memorial particulariza (re)leituras fundadas no conhecimento de si e do grupo de pertença, pois ele socializa saberes. No (re)conto emergem ambivalências, contradições subjacentes ao ser social. Nessa razão, Passeggi (2006b, p. 3) afirma que "as narrativas autobiográficas não são, apenas, descrições ou interpretações de acontecimentos pessoais, mas se constituem uma ação social por meio da qual o indivíduo retotaliza sua trajetória de vida e sua interação com o social".

Elucidando os problemas enfrentados ao longo da vida, as locutoras vão (re)constituindo uma imagem favorável de si e revendo aspectos identitários da figura do professor. Nesse processo de construção do ethos, as professoras-cursistas julgam situações, ações, fatos que devem ser explicitados ou omitidos, o que, por sua vez, faz com que elas se coloquem como objeto de reflexão.

\section{Considerações Finais}

Analisar a realidade educacional se faz imprescindível para a obtenção de objetivos de formação traçados. Tal análise pode ser fruto das experiências propiciadas pelos sujeitos em formação; pela investigação de determinadas temáticas suscitadas nos cursos; pelo confronto da teoria com a prática; pela 
problematização das representações envolvendo a escola, o ensino, o docente e o discente; entre outros fatores. A identidade profissional do professor surge na tensão desses conhecimentos e traz, inevitavelmente, efeitos na relação ensino-aprendizagem, tanto no contexto da universidade, como no contexto escolar.

As Agências de Formação, ao se considerarem os aspectos constitutivos da profissão, devem ter como mote a constituição de um professor reflexivo, os conteúdos exigidos na atuação, a postura ética com relação a seus pares, o envolvimento com as causas da comunidade escolar. Somente através desse viés é possível chegarmos à figura do professor capaz de transformar a sua realidade profissional e a realidade social de seus alunos. A criticidade é elemento imprescindível para uma formação eficaz e só há uma maneira de alcançá-la; escutando o que os envolvidos no processo formativo têm a dizer.

O material verbal é ponto de partida para ajustes, adequações, escolhas de rotas mais pertinentes, mudanças de perspectivas. Nesse sentido, vale citar Bakhtin (2004, p. 41), demonstrando a relação entre a linguagem e as transformações sociais.

As palavras são tecidas a partir de uma multidão de fios ideológicos e servem de trama a todas as relações sociais em todos os domínios. É portanto claro que a palavra será sempre o indicador mais sensível de todas as transformações sociais, mesmo daquelas que apenas despontam, que ainda não tomaram forma, que ainda não abriram caminho para sistemas ideológicos estruturados e bem formados.

Sabemos que a identidade deve ser constituída na experiência; nesse processo, pode-se chegar a uma identidade de classe, algo mais sistemático, que confere unidade a um grupo social. O contexto educacional dará subsídios para pensarmos os elementos essenciais da profissão docente; por essa razão, é preciso conhecê-lo amplamente, visto que "a palavra está sempre carregada de um conteúdo ou de um sentido ideológico ou vivencial. É assim que compreendemos as palavras e somente reagimos àquelas que despertam em nós ressonância ideológicas ou concernentes à vida" (BAKHTIN, 2004, p. 95). 


\section{Referências}

BAKHTIN, M. Os gêneros do discurso: enunciado, unidade da comunicação verbal. In: BAKHTIN, M. Estética da criação verbal. Tradução Maria Ermentina Galvão Pereira. São Paulo: Martins Fontes, 2003.

BAKHTIN, M. Marxismo e filosofia da linguagem. São Paulo: Hucitec, 2004.

DOISE, W.; PALMONARI, A. L'étude des répresentations sociales. Paris:

Delachaux \& Niestlé, 1986.

FILLIETTAZ, L. Actions, activités et discours. 2000. Thése (Doctorat en Linguistique)-Université de Genève, Genève, Suisse.

MACHADO, A. R. (Org.). O ensino como trabalho: uma abordagem discursiva. Londrina: Eduel, 2004.

PASSEGGI, M. da C. F. B. S. A formação do professor na abordagem autobiográfica. A experiência dos memoriais de formação. In:

CONGRESSO INTENACIONAL SOBRE PESQUISA (AUTO)BIOGRÁfICA, 2., Porto Alegre, 2006. Anais... Porto Alegre: Ed. PUCRS; Ed. UNEB, 2006.

PASSEGGI, M. da C. F. B. S. Formação e pesquisa autobiográfica. In: SOUZA, E. C. de. In: CONGRESSO INTERNACIONAL SOBRE PESQUISA (AUTO)BIOGRÁfICA, 2., Porto Alegre. Anais... Porto Alegre: Ed. PUCRS; Ed. UNEB, 2006.

PAVLOSKI, E. Identidades instáveis: os fragmentos do sujeito moderno. In: HARMUCH, R.; SALEH, P. (Org.). Identidade e subjetividade: configurações contemporâneas. Campinas: Mercado de Letras, 2012.

PY, B. Pour une approche linguistique des représentations sociales. Langages: tépresentations métalinguistiques ordinaires et discours, Paris, n. 154, 2004.

Recebido em: 24/08/2015

Aceito: 12/01/2016 